\title{
Nanoslotted microring resonator for high figure of merit refractive index sensing
}

\author{
Daquan Yang ${ }^{1 *}$, Bing DuAn ${ }^{1}$, Xuan Zhang ${ }^{1}$, Hui Lu ${ }^{2 *}$ \\ ${ }^{1}$ State Key Laboratory of Information Photonics and Optical Communication, \\ School of Information and Communication Engineering, \\ Beijing University of Posts and Telecommunications, Beijing 100876, China \\ ${ }^{2}$ Cyberspace Institute of Advanced Technology, Guangzhou University, \\ Guangzhou 510006, China
}

${ }^{*}$ Corresponding authors: ydq@bupt.edu.cn (Daquan Yang), luhui@gzhu.edu.cn (Hui Lu)

\begin{abstract}
A nanoslotted microring resonator (NSMR) with enhanced light-matter interaction has been designed, which can be used for high sensitive refractive index sensing. The performance of the device is investigated theoretically based on a three-dimensional finite-difference time-domain (3D-FDTD) method. In order to achieve high figure of merit sensing, the nanoslot geometry is exploited to make the optical field strongly localized inside the low index region and overlap sufficiently with the analytes. By using the 3D-FDTD method, the proposed NSMR sensor device achieves a high $Q$-factor $\left(Q>10^{5}\right)$ and sensitivity $\sim 100 \mathrm{~nm} / \mathrm{RIU}$ (RIU - refractive index unit). Moreover, the strong light confinement introduced by the nanoslot in NSMR results in the sensor figure of merit as high as $6.73 \times 10^{3}$. Thus, the design we proposed is a promising platform for refractive index-based biochemical sensing and lab-on-a-chip applications.
\end{abstract}

Keywords: nanoslot, microring resonator, refractive index sensor, figure of merit, integrated nanophotonics, 3D-FDTD.

\section{Introduction}

Over the past decades, microring resonators have been widely used in many fields due to their simple manufacturing process, excellent performance, flexible design, and small volume. In order to further enhance the interaction between optical fields and environmental mediums [1-7], nanoslot structures were introduced into the microring resonators, providing strong light confinements and localized field enhancements [ $\underline{8}-\underline{11}]$. Recently, photonic crystal (PC) microring resonators have attracted great attentions for their ultracompact footprint, high $Q$-factor and small mode volume [12-20] . Compared with 2D-PC, 1D-PC nanobeam cavities have emerged as an advantageous platform for on-chip optical technology, owing to their attractive properties such as the ability to confine light in a small volume, convenient integration with bus-waveguides, ultracompact footprint, and ultra-high $Q$-factors [ $\underline{21}-\underline{33}]$. 
However, sensitivity $S$ and $Q$-factor have a trade-off in label-free optical resonator sensors. So far, optical geometry that maximizes both factors is under active development. The sensor figure of merit (FOM) becomes an important parameter to measure the sensing performance, which is defined as the resonance shift upon a change in the refractive index of the dielectric surrounding normalized by the resonance line-width, $\mathrm{FOM}=Q S / \lambda_{\text {res }}[\underline{22}, \underline{23}, \underline{34}]$, where $Q$ is the quality factor of the resonator, $S=\Delta \lambda / \Delta \mathrm{RI}$ characterizes the shift of resonance $\Delta \lambda$ in response to the surrounding index change $\Delta \mathrm{RI}$, and $\lambda_{\text {res }}$ is the cavity resonant wavelength. In order to obtain high FOM, a novel nanoslotted microring resonator (NSMR) with enhanced light-matter interaction is designed, which can be used for high sensitive refractive index sensing. The performance of the device is investigated theoretically based on a three-dimensional finite-difference time-domain (3D-FDTD) method. For the purpose of achieving a FOM sensing, the nanoslot geometry is exploited to make the optical field strongly localized inside the low index region and overlaps sufficiently with the analytes.

\section{Nanoslotted microring resonator design}

Figure 1a shows the schematic and side-view image of a NSMR device. The device is designed from silicon-on-insulator (SOI) with $220 \mathrm{~nm}$ device layer on a $3 \mu \mathrm{m}$ thick

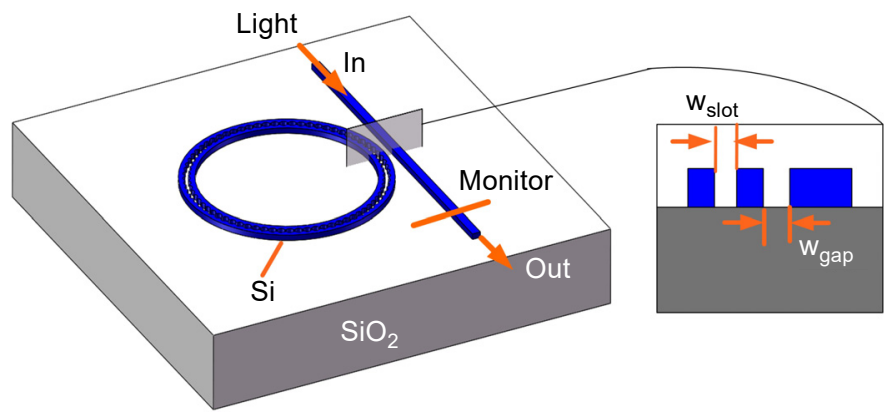

a

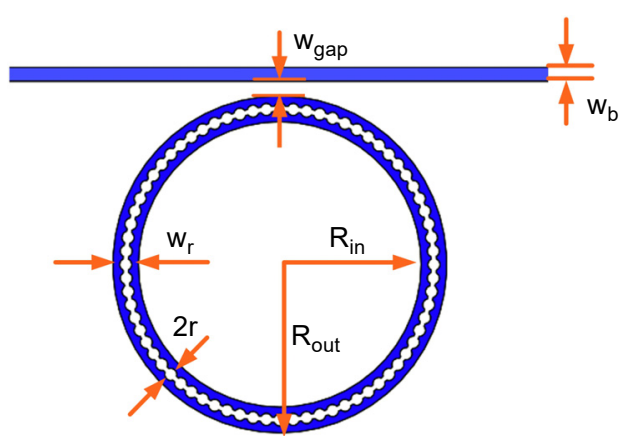

b

Fig. 1. Schematic of NSMR and its side-view ( $w_{\text {slot }}-$ the width of the nanoslot, $w_{\text {gap }}-$ the distance between waveguide and microring resonator) (a). The top-view of NSMR, which consists of bus waveguide and microring resonator ( $w_{\mathrm{b}}$ - the width of waveguide, $w_{\mathrm{r}}$ - the width of microring, $r$ - the hole radius); the blue region is high refractive index material $-\mathrm{Si}(\mathbf{b})$. 
buried oxide (BOX) layer, which is retained to provide mechanically stable support for the NSMR structure. The refractive index of the silicon and silicon oxide substrate are 3.46 and 1.45 , respectively. The background surrounding is air, and the refractive index of air is $n_{\text {air }}=1.0$. As shown in Fig. 1 b, the proposed NSMR consists of two parts, one is a bus waveguide, utilised to couple light into and out the slotted microring waveguide. To achieve effective coupling between the bus waveguide and the microring resonator integrated with slotted waveguide, the width of the bus waveguide is reduced with respect to that of the microring waveguide. The width of the bus waveguide is tapered from both ends with $w_{\mathrm{b}}=2.0 \mu \mathrm{m}$ to the center uniform waist region with $w_{\mathrm{b}}=0.40 \mu \mathrm{m}$. The other is an integrated slotted microring waveguide, $R_{\text {out }}=5.0 \mu \mathrm{m}$, $R_{\text {in }}=4.0 \mu \mathrm{m}$, and the width of microring waveguide is $w_{\mathrm{r}}=1.0 \mu \mathrm{m}$.

According to paper [32], the corresponding properties of bent slotted waveguide modes strongly depend on the slot position. Particularly, the first-order mode is moderately lossy only if the slot is symmetrically positioned within the ring. Thus, the slot is placed symmetrically with the center of the ring. Seventy-two identical air holes are integrated into the slot ring waveguide evenly, forming a periodic structure, to ensure the light is evanescently coupled from the bus waveguide into the microring resonator efficiently [35]. The distance between adjacent air holes is $392.7 \mathrm{~nm}$. According to the conventional design method, the gap ( $\left.w_{\text {gap }}\right)$ between the bus waveguide and microring resonator is set as $150 \mathrm{~nm}$. The air slot width $\left(w_{\text {slot }}\right)$ and hole radius $(r)$ in the microring waveguide are 120 and $130 \mathrm{~nm}$, respectively.

Herein, in the following discussion and simulation, we only consider the TE-polarized modes. The device transmission spectra are calculated by using 3D-FDTD method (Lumerical Solutions Inc.). In the 3D-FDTD simulations, the computations accuracy depends on the mesh accuracy. Here, the mesh accuracy in the 3D-FDTD simulation is chosen as 4 , which is a good trade-off between accuracy, memory requirements and

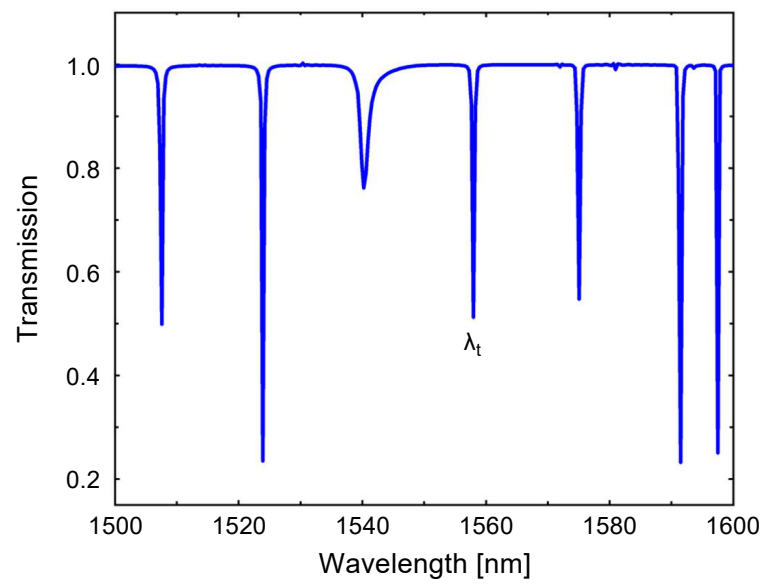

a

Fig. 2. The optical transmission spectrum of the proposed NSMR device obtained by using 3D-FDTD simulations (a). Enlarged spectra of resonance $\lambda_{\mathrm{t}}=1557.97 \mathrm{~nm}$ showing a high quality factor. Inset: $3 \mathrm{D}-\mathrm{FDTD}$ simulation of major field distribution of a specific targeted resonance mode (b). 


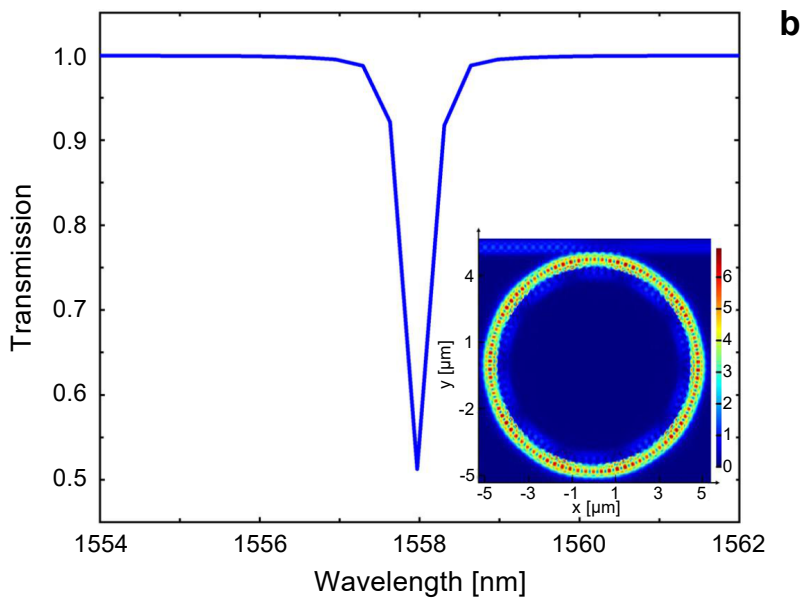

Fig. 2. Continued.

simulations time [36]. And the mesh size is: $x=0.024 \mu \mathrm{m}, y=0.027 \mu \mathrm{m}, z=0.05 \mu \mathrm{m}$. Figure 2a shows the 3D-FDTD transmission spectrum of the proposed NSMR device with the wavelength changes from 1500 to $1600 \mathrm{~nm}$. Non-uniform free-spectral range (FSR) between adjacent resonances is affected by a slow-light effect [37-40]. The $Q$-factor of these cavities can be defined as $1 / Q=P /\left(\omega_{0} U\right)$, where $P$ is the outgoing energy, $U$ is the electromagnetic energy localized in the cavity, $\omega_{0}$ is the frequency of light around the cavity [41]. Obviously, the more energy is stored in the cavity, the higher $Q$-factor will be realised. Therefore, in order to achieve a higher $Q$-factor, the optical mode should be more localized in the center of cavities [년 $\underline{43}]$. As shown in the inset of Fig. 2b, most of the optical energy is localized in the center of cavities when $\lambda_{\mathrm{t}}=1557.97 \mathrm{~nm}$. Consequently, we choose $\lambda_{\mathrm{t}}$ as the target mode resonance.

\section{Optimization and discussion}

Herein, to achieve a higher $Q$-factor, we optimize the design of NSMR by changing three structure parameters, i.e., air holes radius, slot width in the microring waveguide, and gap width between the mircoring resonator and bus waveguide. The first step in the optimization process is to determine the radius of air holes. Figure $3 \mathbf{a}$ shows the simulation results for $Q$-factor as a function of air holes radius $r$. Obviously, when $r=110 \mathrm{~nm}$, the $Q$-factor reaches the highest level $6.79 \times 10^{4}$. Therefore, we selected the holes radius as $110 \mathrm{~nm}$.

Intrinsically, slot waveguide is known to suffer from larger roughness-induced scattering extrinsic losses than $\mathrm{Si}$ waveguide due to a strong electric field interaction with the inner rails' walls, which is determined by lithographic and etching technological processes. Hence, different ratios of slot width $w_{\text {slot }}$ to total slotted waveguide width lead to different linear loss and $Q$-factors. So it is necessary for us to investigate the relationship between $Q$-factor and $w_{\text {slot }}$. As shown in Fig. $3 \mathbf{b}$, the microring maximum 

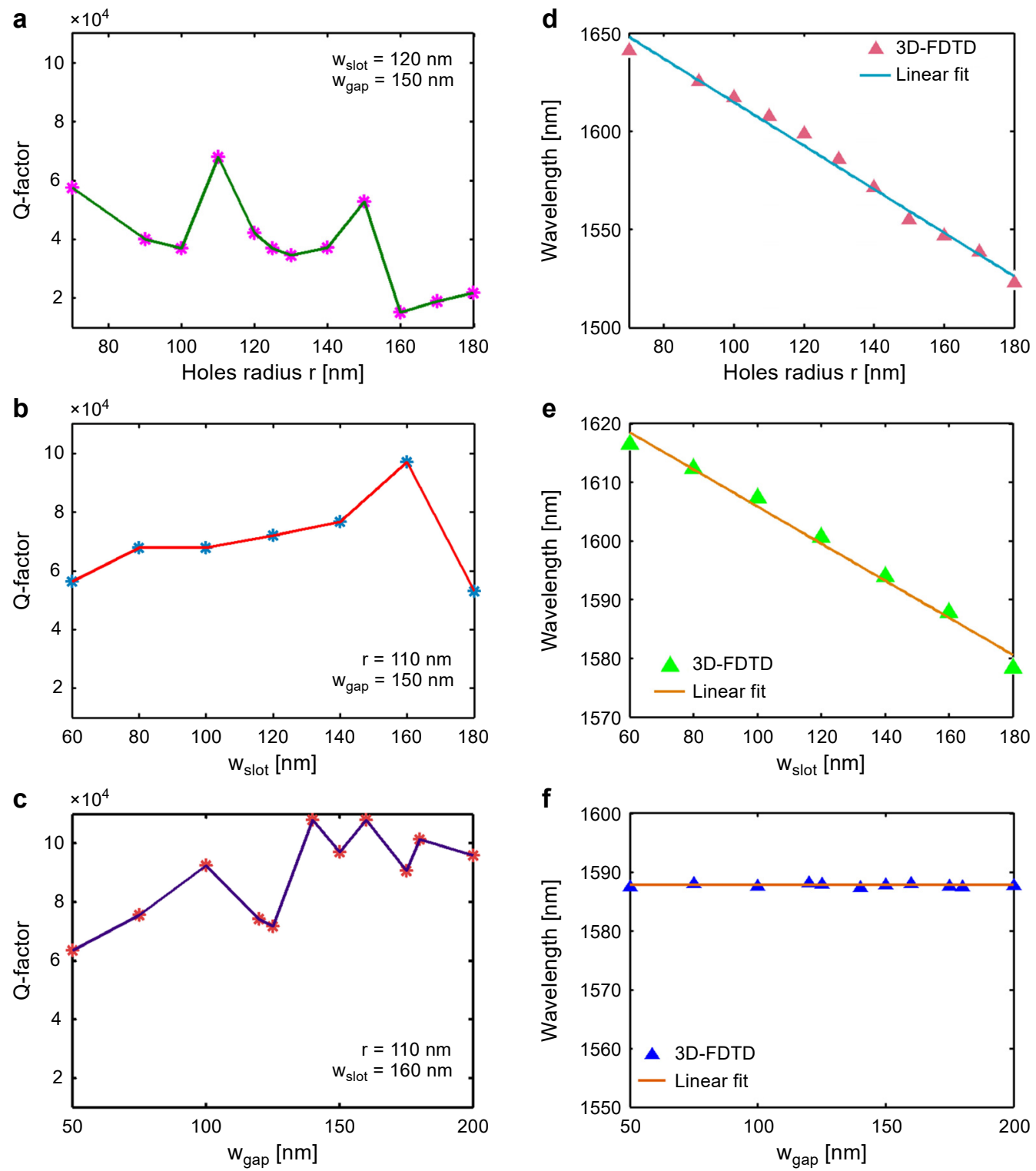

Fig. 3. The 3D-FDTD simulation results for $Q$-factor as a function of air hole radius (a), air slot width (b) and gap width (c). The linear least-squares fit figures of resonance wavelength varying with increased holes radius (d), air slot width (e), and gap width (f).

theoretical $Q$-factor greatly increases up to $9.71 \times 10^{4}$ when $w_{\text {slot }}=160 \mathrm{~nm}, r=110 \mathrm{~nm}$. Therefore, optimum parameters of $w_{\text {slot }}$ should be $160 \mathrm{~nm}$.

Based on the optimization parameters mentioned above, it is shown in Fig. 3c that $Q$-factor varies with gap width $w_{\text {gap }}$, corresponding with what is exhibited in [10]. The microring $Q$-factor greatly increases up to $10.8 \times 10^{4}$ when the coupler gap 


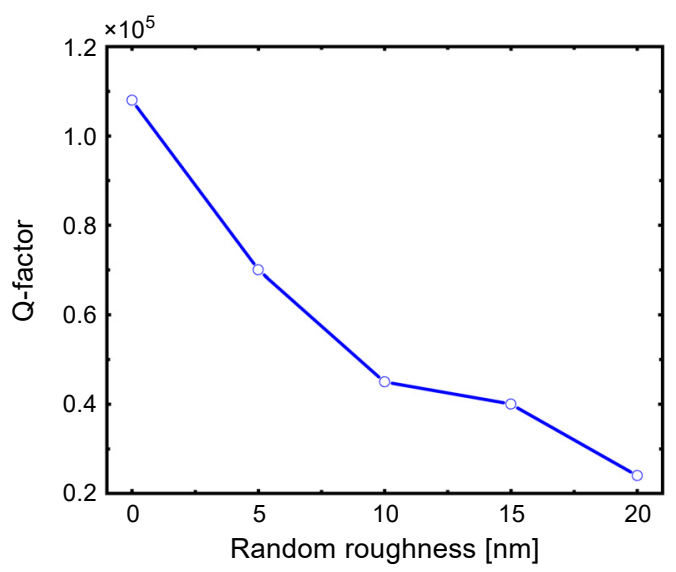

Fig. 4. The effect of fabrication roughness on the $Q$-factors. A random distribution of roughness from 0 to 5 , to 10 , to 15 , and to $20 \mathrm{~nm}$, respectively, is simulated. The cavity is immersed in air environment with refractive index of $\mathrm{RI}=1.00$.

$w_{\text {gap }}=160 \mathrm{~nm}$, meaning that the coupler losses have been reduced significantly. This phenomenon is probably due to the minimization of the waveguide sidewall scattering loss effects of coupler gaps.

Figures $3 \mathbf{d}-3 \mathbf{f}$ show the relationship between target resonance wavelength (corresponding to the highest $Q$-factor) and air hole radius, air slot width, and gap width, respectively. It can be seen from Figs. $\mathbf{3} \mathbf{d}$ and $3 \mathbf{e}$, that all resonant wavelengths experience blue shift at a constant rate with the increased filling factor $f$ contributed by expanded air holes and slot. Unlike Figs. 3d and 3e, Fig. 3f shows that the change of gap width has little effect on wavelength shift. Finally, the optimized air holes radius, slot width, and gap width of NSMR are 110,160 , and $160 \mathrm{~nm}$, respectively. The $Q$-factor as high as $10.8 \times 10^{4}$ can be obtained with the resonant wavelength at $1588.02 \mathrm{~nm}$.

In addition, we also consider the effect of the fabrication roughness (e.g., sidewall roughness) in our design. Our simulation was done in air, assuming a random distribution of roughness from 0 to 5 , to 10 , to 15 , and to $20 \mathrm{~nm}$, respectively. It can be seen from Fig. 4 that $Q$-factor decreases from $10^{5}$ to $10^{4}$. But in the practical biosensing application, the water absorption have to be taken into account, and the absorption $Q$ will be limited to the order of $10^{4}$ [44] at telecom wavelength range. Therefore, in the practical biosensing application, fabrication roughness is not the major factor limiting $Q$ relative to water absorption.

\section{Simulated transmission and RI sensitivity of the optimized sensor}

Figure 5 displays the composed transmission spectra as a function of increased refractive index changed from $\mathrm{RI}=1.00$ to $\mathrm{RI}=1.40$ with the step $\Delta \mathrm{RI}=0.05$. All resonant wavelengths shift towards longer wavelength (namely, red-shift) as the function of the re- 


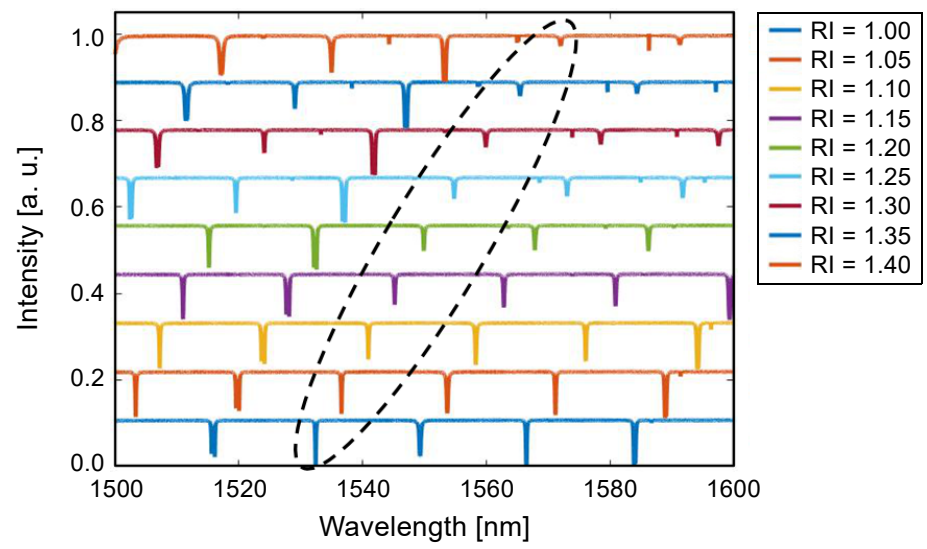

Fig. 5. The 3D-FDTD transmission spectra as the background RI changes from $\mathrm{RI}=1.00$ to $\mathrm{RI}=1.40$ with step size 0.05 .

fractive index increased. However, as seen from Fig. 5, in the investigated wavelength range, there are multiple resonances in the transmission spectrum. As the refractive index changes, the resonance shift is larger than the distance between the consecutive resonances. This will result in erroneously identifying the selected target resonance. In order to solve this problem, a method demonstrated in our previous work [22] can be used, namely, we can introduce PC nanobeam bandgap filters in the both input and output ports of the bus waveguide, respectively. Then, a transmission spectrum only containing the selected target resonance for sensing purposes is created, while the other resonances are filtered out. Thus, for application as a sensor, the selected target resonance can be tracked accurately without erroneously identifying.

Next, to quantitatively analyze the refractive index RI sensitivity of the proposed sensor device, we choose the sensitivity $S$ of our device by observing the shifts in the

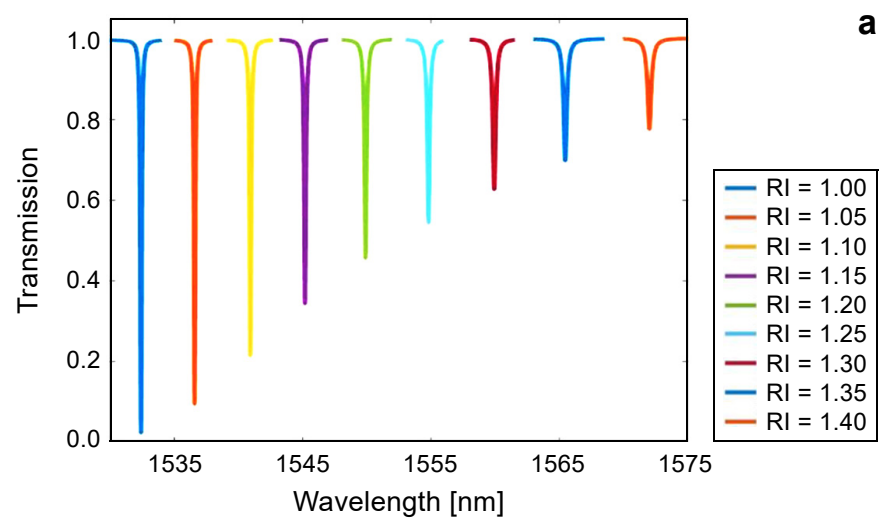

Fig. 6. Transmission spectra of the NSMR when the background refractive index changes from RI $=1.00$ to $\mathrm{RI}=1.40$ with a step size 0.05 (a). Shift of the microring resonator as a function of increased refractive index (b). 


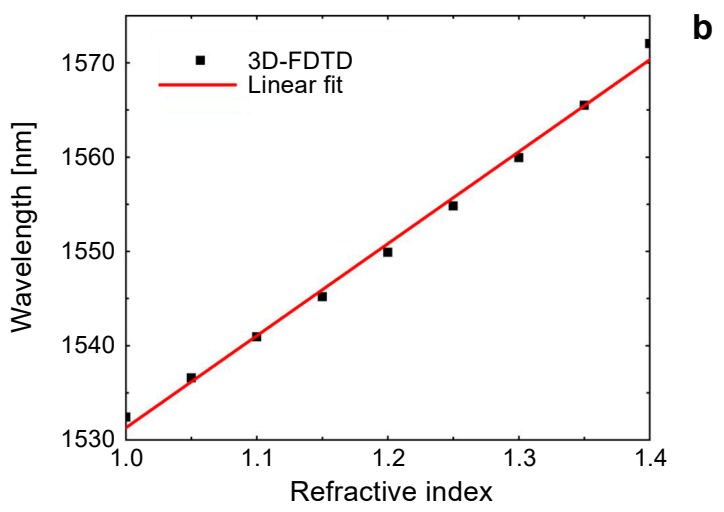

Fig. 6. Continued.

resonant wavelength of the sensor as a function of the variations in the refractive index. The shift of the peak resonant wavelength $\Delta \lambda$ is a function of the change in the refractive index $\Delta \mathrm{RI}$, the sensor RI-sensitivity is expressed as $S=\Delta \lambda / \Delta \mathrm{RI}$. Figure 6a shows the selected target resonant wavelength $\lambda_{\text {res }}$ shift (namely, ellipse region in Fig. 5) when the background $\mathrm{RI}$ varies from $\mathrm{RI}=1.00$ to $\mathrm{RI}=1.40(\Delta \mathrm{RI}=0.40)$. Figure $6 \mathbf{b}$ shows the linear fit of the resonant wavelength shift (red-shift) with the increased RI. According to Fig. $6 \mathbf{b}$, the resonant wavelength shift of the proposed sensor is $\Delta \lambda=39.61 \mathrm{~nm}$. Consequently, the calculated RI sensitivity is $99.03 \mathrm{~nm} / \mathrm{RIU}$, resulting in the optimized FOM as high as $6.73 \times 10^{3}$.

\section{Conclusions}

In summary, we presented a novel nanoslotted photonic crystal microring resonator for high figure of merit refractive index sensing. By using the 3D-FDTD method, the simulation results show that high $Q$-factor $\left(Q>10^{5}\right)$ and sensitivity of $99.03 \mathrm{~nm} / \mathrm{RIU}$ of the proposed NSMR-based sensor device are obtained. Moreover, the sensor FOM as high as $6.73 \times 10^{3}$ is observed, which benefits from the enhanced light-matter interaction due to the strong optical confinement introduced by the nanoslot in the NSMR. In addition, the footprint of the proposed sensor device is compact, which is a promising platform for refractive index-based sensing and lab-on-a-chip applications.

Acknowledgments - The authors thank A.F. Lodhi for improving the English of the paper. This research was supported by the Fundamental Research Funds for the Central Universities (2018XKJC05); Fund of the State Key Laboratory of Information Photonics and Optical Communications (IPOC2017ZT05), Beijing University of Posts and Telecommunications, PR China.

\section{References}

[1] Xia F., Rooks M., SeKaric L., Vlasov Y., Ultra-compact high order ring resonator filters using submicron silicon photonic wires for on-chip optical interconnects, Optics Express 15(19), 2007, pp. 11934-11941, DOI: 10.1364/OE.15.011934. 
[2] Xu D.-X., Vachon M., Densmore A., Ma R., Delâge A., Janz S., Lapointe J., Li Y., Lopinski G., Zhang D., Liu Q.Y., Cheben P., Schmid J.H., Label-free biosensor array based on silicon-on-insulator ring resonators addressed using a WDM approach, Optics Letters 35(16), 2010, pp. 2771-2773, DOI: $10.1364 /$ OL.35.002771.

[3] Iqbal M., Gleeson M., Spaugh B., Tybor F., Gunn W., Hochberg M., Baehr-Jones T., Bailey R., GunN L.C., Label-free biosensor arrays based on silicon ring resonators and high-speed optical scanning instrumentation, IEEE Journal of Selected Topics in Quantum Electronics 16(3), 2010, pp. 654-661, DOI: 10.1109/JSTQE.2009.2032510.

[4] QAvi A.J., Kindt J.T., Gleeson M.A., Bailey R.C., Anti-DNA:RNA antibodies and silicon photonic microring resonators: increased sensitivity for multiplexed microRNA detection, Analytical Chemistry 83(15), 2011, pp. 5949-5956, DOI: 10.1021/ac201340s.

[5] Vos K.D., Bartolozzi I., Schacht E., Bienstman P., Baets R., Silicon-on-insulator microring resonator for sensitive and label-free biosensing, Optics Express 15(12), 2007, pp. 7610-7615, DOI: 10.1364/OE.15.007610.

[6] Liang F., Clarke N., Patel P., Loncar M., Quan Q., Scalable photonic crystal chips for high sensitivity protein detection, Optics Express 21(26), 2013, pp. 32306-32312, DOI: 10.1364/OE.21.032306.

[7] Hu S., Qin K., Kravchenko I.I., Retterer S.T., Weiss S.M., Suspended micro-ring resonator for enhanced biomolecule detection sensitivity, Proceedings of SPIE 8933, 2014, article 893306, DOI: $10.1117 / 12.2041056$.

[8] Hiremath K.R., Niegemann J., Busch K., Analysis of light propagation in slotted resonator based systems via coupled-mode theory, Optics Express 19(9), 2011, pp. 8641-8655, DOI: 10.1364/OE.19. $\underline{008641 .}$.

[9] Gylfason K.B., Carlborg C.F., Kaźmierczak A., Dortu F., Sohlström H., Vivien L., Barrios C.A., VAn der WijngaArt W., Stemme G., On-chip temperature compensation in an integrated slot-waveguide ring resonator refractive index sensor array, Optics Express 18(4), 2010, pp. 3226-3237, DOI: 10.1364/OE.18.003226.

[10] Zhang W., Serna S., Roux X.L., Alonso-Ramos C., Vivien L., Cassan E., Analysis of silicon-on-insulator slot waveguide ring resonators targeting high Q-factors, Optics Letters 40(23), 2015, pp. 5566 -5569, DOI: 10.1364/OL.40.005566.

[11] Claes T., Molera J.G., De Vos K., Schacht E., Baets R., Bienstman P., Label-free biosensing with a slot-waveguide-based ring resonator in silicon on insulator, IEEE Photonics Journal 1(3), 2009, pp. 197-204, DOI: 10.1109/JPHOT.2009.2031596.

[12] Lee M., Fauchet P.M., Two-dimensional silicon photonic crystal based biosensing platform for protein detection, Optics Express 15(8), 2007, pp. 4530-4535, DOI: 10.1364/OE.15.004530.

[13] Kang C., Phare C.T., Vlasov Y.A., Assefa S., Weiss S.M., Photonic crystal slab sensor with enhanced surface area, Optics Express 18(26), 2010, pp. 27930-27937, DOI: 10.1364/OE.18.027930.

[14] LeE M.R., FAUChEt P.M., Nanoscale microcavity sensor for single particle detection, Optics Letters 32(22), 2007, pp. 3284-3286, DOI: 10.1364/OL.32.003284.

[15] Buswell S.C., Wright V.A., Buriak J.M., Van V., Evoy S., Specific detection of proteins using photonic crystal waveguides, Optics Express 16(20), 2008, pp. 15949-15957, DOI: 10.1364/OE.16. 015949.

[16] Kang C., Weiss S.M., Vlasov Y.A., Assefa S., Optimized light-matter interaction and defect hole placement in photonic crystal cavity sensors, Optics Letters 37(14), 2012, pp. 2850-2852, DOI: 10.1364/OL.37.002850.

[17] Bogaerts W., Baets R., Dumon P., Wiaux V., Beckx S., Taillaert D., Luyssaert B., Van Campenhout J., Bienstman P., Van Thourhout D., Nanophotonic waveguides in silicon-oninsulator fabricated with CMOS technology, Journal of Lightwave Technology 23(1), 2005, pp. 401412, DOI: $10.1109 / \mathrm{JLT} .2004 .834471$.

[18] Pal S., Guillermain E., Sriram R., Miller B.L., Fauchet P.M., Silicon photonic crystal nanocavity -coupled waveguides for error-corrected optical biosensing, Biosensors and Bioelectronics 26(10), 2011, pp. 4024-4031, DOI: 10.1016/j.bios.2011.03.024. 
[19] Ogusu K., Takayama K., Optical bistability in photonic crystal microrings with nonlinear dielectric materials, Optics Express 16(10), 2008, pp. 7525-7539, DOI: 10.1364/OE.16.007525.

[20] YANG D., ZHANG X., Design of freely suspended photonic crystal microfiber cavity sensors array in a general single mode fiber, Optics Communications 435, 2019, pp. 11-15, DOI: 10.1016/j.optcom. 2018.11.019.

[21] Quan Q., Loncar M., Deterministic design of wavelength scale, ultra-high Q photonic crystal nanobeam cavities, Optics Express 19(19), 2011, pp. 18529-18542, DOI: 10.1364/OE.19.018529.

[22] YANG D., WANG C., JI Y., Silicon on-chip one-dimensional photonic crystal nanobeam bandgap filter integrated with nanobeam cavity for accurate refractive index sensing, IEEE Photonics Journal 8(2), 2016, article 4500608, DOI: 10.1109/JPHOT.2016.2536942.

[23] Yang D., Tian H., Ji Y., High-Q and high-sensitivity width-modulated photonic crystal single nanobeam air-mode cavity for refractive index sensing, Applied Optics 54(1), 2015, pp. 1-5, DOI: 10.1364/AO.54.000001.

[24] Kim S., Kim H.-M., LeE Y.-H., Single nanobeam optical sensor with a high Q-factor and high sensitivity, Optics Letters 40(22), 2015, pp. 5351-5354, DOI: 10.1364/OL.40.005351.

[25] Makino S., Sato T., Ishizaka Y., Fujisawa T., Saitoh K., Three-dimensional finite-element time -domain beam propagation method and its application to 1-D photonic crystal-coupled resonator optical waveguide, Journal of Lightwave Technology 33(18), 2015, pp. 3836-3842, DOI: 10.1109 / JLT.2015.2446514.

[26] Hendrickson J., Soref R., Sweet J., Buchwald W., Ultrasensitive silicon photonic-crystal nanobeam electro-optical modulator: design and simulation, Optics Express 22(3), 2014, pp. 3271-3283, DOI: 10.1364/OE.22.003271.

[27] Lai W.-C., Chakravarty S., Zou Y., Chen R.T., Silicon nano-membrane based photonic crystal microcavities for high sensitivity bio-sensing, Optics Letters 37(7), 2012, pp. 1208-1210, DOI: 10.1364/OL.37.001208.

[28] Yang D., Zhang P., Tian H., Ji Y., Quan Q., Ultrahigh-Q and low-mode-volume parabolic radius -modulated single photonic crystal slot nanobeam cavity for high-sensitivity refractive index sensing, IEEE Photonics Journal 7(5), 2015, article 4501408, DOI: 10.1109/JPHOT.2015.2476761.

[29] Ryckman J.D., Weiss S.M., Localized field enhancements in guided and defect modes of a periodic slot waveguide, IEEE Photonics Journal 3(6), 2011, pp. 986-995, DOI: 10.1109/JPHOT.2011.2170966.

[30] Lin T., Zhang X., Zhou G., Siong C.F., Deng J., Design of an ultra-compact slotted photonic crystal nanobeam cavity for biosensing, Journal of the Optical Society of America B 32(9), 2015, pp. 1788 -1791, DOI: $\underline{10.1364 / \mathrm{JOSAB} .32 .001788 .}$.

[31] Wang C., Quan Q., Kita S., Li Y., Lončar M., Single-nanoparticle detection with slot-mode photonic crystal cavities, Applied Physics Letters 106(26), 2015, article 261105, DOI: 10.1063/ 1.4923322.

[32] Scullion M.G., Di Falco A., Krauss T.F., Slotted photonic crystal cavities with integrated microfluidics for biosensing applications, Biosensors and Bioelectronics 27(1), 2011, pp. 101-105, DOI: 10.1016/j.bios.2011.06.023.

[33] Yang D., Gao F., CaO Q.-T., Wang C., Ji Y., Xiao Y.-F., Single nanoparticle trapping based on on-chip nanoslotted nanobeam cavities, Photonics Research 6(2), 2018, pp. 99-108, DOI: 10.1364/ PRJ.6.000099.

[34] Sherry L.J., Chang S.-H., Schatz G.C., Van Duyne R.P., Wiley B.J., Xia Y., Localized surface plasmon resonance spectroscopy of single silver nanocubes, Nano Letters 5(10), 2005, pp. 2034-2038, DOI: $10.1021 / \mathrm{nl} 0515753$.

[35] Urbonas D., BalČytis A., VašKevičius K., Gabalis M., Petrušrevičıus R., Air and dielectric bands photonic crystal microringresonator for refractive index sensing, Optics Letters 41(15), 2016, pp. 3655-3658, DOI: 10.1364/OL.41.003655.

[36] http://www.lumerical.com (accessed October 2018). 
[37] LeE J.Y., FAuchet P.M., Slow-light dispersion in periodically patterned silicon microring resonators, Optics Letters 37(1), 2012, pp. 58-60, DOI: 10.1364/OL.37.000058.

[38] McGarvey-Lechable K., Bianucci P., Maximizing slow-light enhancement in one-dimensional photonic crystal ring resonators, Optics Express 22(21), 2014, pp. 26032-26041, DOI: 10.1364/OE. 22.026032.

[39] McGarvey-Lechable K., Hamidfar T., Patel D., Xu L., Plant D.V., Bianucci P., Slow light in mass-produced, dispersion-engineered photonic crystal ring resonators, Optics Express 25(4), 2017, pp. 3916-3926, DOI: 10.1364/OE.25.003916.

[40] Chakravarty S., Zou Y., Lai W.-C., Chen R.T., Slow light engineering for high Q high sensitivity photonic crystal microcavity biosensors in silicon, Biosensors and Bioelectronics 38(1), 2012, pp. 170 -176, DOI: 10.1016/j.bios.2012.05.016.

[41] Joannopoulos J.D., Johnson S.G., Winn J.N., Meade R.D., Photonic Crystals: Molding the Flow of Light, 2nd Ed., Princeton University Press, Princeton, NJ, USA, 2008.

[42] Yang D., Tian H., JI Y., Quan Q., Design of simultaneous high-Q and high-sensitivity photonic crystal refractive index sensors, Journal of the Optical Society of America B 30(8), 2013, pp. 2027-2031, DOI: 10.1364/JOSAB.30.002027.

[43] Almeida V.R., Xu Q., Barrios C.A., Lipson M., Guiding and confining light in void nanostructure, Optics Letters 29(11), 2004, pp. 1209-1211, DOI: 10.1364/OL.29.001209.

[44] Armani A.M., Vahala K.J., Heavy water detection using ultra-high-Q microcavities, Optics Letters 31(12), 2006, pp. 1896-1898, DOI: 10.1364/OL.31.001896.

Received October 11, 2018

in revised form February 23, 2019 